\title{
Early Alteration of Structural and Functional Brain Development in Premature Infants Born with Intrauterine Growth Restriction
}

\author{
CRISTINA BORRADORI TOLSA, SLAVA ZIMINE, SIMON K. WARFIELD, MONICA FRESCHI, \\ ANA SANCHO ROSSIGNOL, FRANCOIS LAZEYRAS, SYLVIANE HANQUINET, \\ MIRJAM PFIZENMAIER, AND PETRA S. HÜPPI
}

Child Development Unit, Department of Pediatrics, Children's Hospital, 1211 Geneva, Switzerland [C.B.T., M.F., A.S.R., P.S.H.], Department of Radiology [S.Z., F.L., S.H.], Department of Obstetrics and

Gynaecology [M.P.], University Hospital, 1211 Geneva, Switzerland, and Computational Radiology Laboratory, Department of Radiology, Brigham and Women's Hospital, Harvard Medical School, Boston, MA 02115, U.S.A. [S.K.W.]

\begin{abstract}
ABSTR
Placental insufficiency with fetal intrauterine growth restriction
(IUGR) is an important cause of perinatal mortality and morbidity
and is subsequently associated with significant neurodevelopmental
impairment in cognitive function, attention capacity, and school
performance. The underlying biologic cause for this association is
unclear. Twenty-eight preterm infants (gestational age $32.5 \pm 1.9$
wk) were studied by early and term magnetic resonance imaging
(MRI). An advanced quantitative volumetric three-dimensional
MRI technique was used to measure brain tissue volumes in 14
premature infants with placental insufficiency, defined by abnormal
antenatal Doppler measurements and mean birth weights $<10^{\text {th }}$
percentile (1246 $\pm 299 \mathrm{~g}$ ) (IUGR) and in 14 preterm infants
matched for gestational age with normal mean birth weights $1843 \pm$
$246 \mathrm{~g}$ (control). Functional outcome was measured at term in all
infants by a specialized assessment scale of preterm infant behavior.
Premature infants with IUGR had a significant reduction in intra-
cranial volume (mean \pm SD: $253.7 \pm 29.9$ versus $300.5 \pm 43.5 \mathrm{~mL}$,
$p<0.01$ ) and in cerebral cortical gray matter (mean \pm SD: $77.2 \pm$
16.3 versus $106.8 \pm 24.6 \mathrm{~mL}, p<0.01$ ) when measured within the
first 2 wk of life compared with control premature infants. These
findings persisted at term with intracranial volume (mean \pm SD:
$429.3 \pm 47.9$ versus $475.9 \pm 53.4$ mL, $p<0.05$ ) and cerebral
cortical gray matter (mean $\pm \mathrm{SD}: 149.3 \pm 29.2$ versus $189 \pm 34.2$
\end{abstract}
An increasing number of developmental disorders $(1,2)$ and diseases $(3,4)$ in child and adult life are thought to have their origin in the fetal period. Central to this predisposition is fetal

Received July 28, 2003; accepted January 30, 2004.

Correspondence: Petra S. Hüppi, M.D., Child Development Unit, Department of Pediatrics, University Children's Hospital, Rue Willy-Donzé 6, 1211 Geneva, Swizerland: e-mail: Petra.Huppi@hcuge.ch

Supported by the Swiss National Science Foundation, grant No. 32-56927.99 (P.S.H.) and, in part, by National Institutes of Health grant P41 RR13218, and by a research grant from the Whitaker Foundation (S.K.W.).

DOI: 10.1203/01.PDR.0000128983.54614.7E
$\mathrm{mL}, p<0.01)$. Behavioral assessment at term showed a significantly less mature score in the subsystem of attention-interaction availability in IUGR infants $(p<0.01)$. Cerebral cortical gray matter volume at term correlated with attention-interaction capacity measured at term $(r=0.45, p<0.05)$. These results suggest that placental insufficiency with IUGR have specific structural and functional consequences on cerebral cortical brain development. These findings may provide insight into the structural-functional correlate for the developmental deficits associated with IUGR. (Pediatr Res 56: 132-138, 2004)

\section{Abbreviations}

IUGR, intrauterine growth restriction

MR, magnetic resonance

MRI, magnetic resonance imaging

CSF, cerebrospinal fluid

MWM, myelinated white matter

UMWM, unmyelinated white matter

CGM, cortical gray matter

SGM, subcortical gray matter

ICV, total intracranial volume

APIB, Assessment of Preterm Infant Behavior growth (5). The fetus receives its nutrients from the maternal/ uterine circulation via the placenta. Any disturbance in the placental-fetal circulation will therefore have severe consequences on the supply of important nutrients such as oxygen, glucose, and amino acids (6). The placenta itself is also an active endocrine organ and, therefore, changes in nutrient availability will also affect placental and, potentially, fetal endocrine function, in particular, the modification of the hypothalamo-pituitary-adrenal axis $(7,8)$. Placental insufficiency, which is the most common cause of IUGR, has further been shown to be associated with a considerable perinatal mortality 
and long-term morbidity $(9,10)$. Multiple follow-up studies of infants with IUGR have shown that fetal IUGR is associated with significant neurodevelopmental disabilities in fine and gross motor skills, cognitive function, activity, self-regulation, language, abstract reasoning, recognition memory, concentration, attention, mood, and school performance in both preterm and term infants $(2,11-17)$. Neurostructural correlations with these observed developmental disabilities in the human, which would help to understand the underlying mechanisms, are missing.

There is strong experimental evidence for a deleterious effect of placental insufficiency on fetal brain development (18). Recent animal studies clearly demonstrated the negative impact of chronic intrauterine hypoxia and protein restriction on cell number and cell size, with overall lighter brain weight and lower DNA content as well as reduced synapse numbers (19-21).

The objective of this study was to use quantitative volumetric three-dimensional (3D) MRI techniques and neurobehavioral assessment to measure the impact of IUGR with placental insufficiency on brain growth, brain tissue composition, and brain functioning during early human brain development in premature newborns.

\section{SUBJECTS AND METHODS}

Subjects. Premature infants born with IUGR and placental insufficiency were consecutively identified and recruited for MRI studies and neurobehavioral assessment. The study was approved by the medical ethical review board of our hospital and written informed consent was obtained from all parents. For each infant with IUGR, defined as birth weight below the $10^{\text {th }}$ percentile for gestational age and gender (22), and abnormal Doppler values within the umbilical artery, one control infant (appropriate-for-gestational-age, and normal flow in the umbilical artery) matching for gestational age at birth was identified. Gestational age was determined using ultrasonography in early pregnancy.

Doppler ultrasonography was used to monitor fetomaternal blood exchanges and the fetal hemodynamic state, by measuring the resistance index (RI) and systolic/diastolic velocities $(\mathrm{S} / \mathrm{D})$ in both maternal uterine arteries and fetal vessels [umbilical artery (UA), middle cerebral artery (MCA), ductus venosus, ductus arteriosus, and aortic isthmus]. These measurements were repeated until delivery. Infants were recruited as follows: the first inclusion criterion was IUGR defined by fetal measurements between 20 and 36 wk of pregnancy. The second inclusion criterion was the presence of placental insufficiency, defined as a resistance to arterial umbilical flow higher than the $95^{\text {th }}$ percentile measured by the two indexes (RI and S/D) within one (the last) or several measurements (23). Infants were delivered prematurely for risk of fetal distress or increased maternal risk.

Our study population included 28 preterm infants. Fourteen infants with placental insufficiency and mean birth weights $<10^{\text {th }}$ percentile $(1246 \pm 299 \mathrm{~g})$ (IUGR) with gestational age (GA) at birth of $32.2 \pm 2.2 \mathrm{wk}$, were compared with 14 infants matched for GA with mean birth weights $1843 \pm 246 \mathrm{~g}$ (control) with GA at birth of $32.8 \pm 1.6$ wk. Head circumferences at birth were significantly different in the two groups $(27.4 \pm 1.6 \mathrm{~cm}$ in IUGR infants versus $29.8 \pm 1.8 \mathrm{~cm}$ in control infants, $p<0.001$ ).

Eight IUGR preterm infants and 11 control preterm infants had received one or two courses of antenatal corticosteroids for lung maturation. Primary adaptation was not different in the two groups: Apgar at 5 min $(9 \pm 0.6$, versus $9 \pm 0.5)$, and umbilical artery $\mathrm{pH}(7.23 \pm 0.08$, versus $7.24 \pm 0.07)$. Infants included in the analysis had a normal standard neurologic examination and were free of cerebral pathology, such as intraventricular hemorrhage, ventriculomegaly, or white matter injury assessed by early ultrasound and early MRI. One infant initially recruited was diagnosed with periventricular leukomalacia and was excluded from the current analysis. No differences in initial neonatal illness severity were found between IUGR and controls. Infants with respiratory distress syndrome requiring intubation and mechanical ventilation, malformations, sepsis, and severe hypoglycemia were also excluded. All infants were started on enteral feeding, breast milk and/or formula, on the first or second day of life.

The initial MRI examination was undertaken in all premature infants within postconceptional age the first $2 \mathrm{wk}$ of life (Early MRI-IUGR: $33.7 \pm 1.4 \mathrm{wk}$ postconceptional age (PCA), controls: $34.3 \pm 1.5$ wk PCA). An advanced quantitative volumetric 3D-MRI analysis technique was used to quantify cerebral tissue volumes. Both a full repeat MR imaging examination and a specific neurobehavioral examination (APIB) were performed at due date (Term MRI-IUGR: 40.1 \pm 0.6 wk PCA, controls: $40 \pm 0.6$ wk PCA).

Methods. For the MR studies, the infants were accompanied by a physician specialized in newborn care to the MRI suite. They were positioned in a vacuum pillow inside the scanner and monitored with ECG and pulse oximetry (Odam and Bruker, Wissembourg, France). Earmuffs (Natus Medical Inc., San Carlos, CA, U.S.A.) were used to minimize noise exposure. No sedation was used for any of the studies. Achieved image quality was excellent, with an absence of motion artifact and excellent contrast of gray matter, white matter, and CSF.

MR image acquisition. MRI scanning was performed using a 1.5 T Marconi (Philips Medical Systems, Andover, MA, U.S.A.) MR system. For the acquisition of the primary MRI data, two different imaging modes were applied: a 3D Fouriertransform fast gradient recalled sequence $(1.5-\mathrm{mm}$ coronal slices, flip angle $25^{\circ}$, repetition time $15 \mathrm{~ms}$, echo time $4.4 \mathrm{~ms}$, field of view $18 \mathrm{~cm}$, matrix $256 \times 256$ ) and a double-echo (proton density and T2-weighted) spin-echo sequence (1.5-mm coronal slices, repetition time $3500 \mathrm{~ms}$, echo times 30 and 150 $\mathrm{ms}$, field of view $18 \mathrm{~cm}$, matrix $256 \times 256$, interleaved acquisition). The voxel (volume of pixel) dimensions for both acquisitions were $0.7 \times 0.7 \times 1.5 \mathrm{~mm}$.

MR image processing. Images were analyzed on workstations (Sun Microsystems, Mountain View, CA, U.S.A.) by an established postacquisition image processing protocol previously described and validated by our group (24-26). The protocol is based on mathematical algorithms designed to reduce imaging noise to align gradient-echo images, T2weighted, and proton-density 3D data sets to classify cerebral 
tissue according to signal behavior and anatomic localization, and, finally, to estimate volume for each tissue class to compute absolute volumes of CGM, SGM, UMWM, MWM, and CSF. Absolute volumes of each cerebral tissue were determined, and these absolute volumes were also referenced to the total ICV and, thereby, reported as relative percentage of each cerebral tissue within the intracranial cavity (\% ICV).

Neurobehavioral assessment. Functional neurologic outcome was measured by a specialized neurobehavioral assessment at term. The APIB is a behavioral assessment tool specifically designed for the documentation of brain functioning in preterm infants in the newborn period. The APIB is a modification of the standardized Brazelton Neonatal Behavioral Assessment Scale (27) and has itself been standardized in various studies $(28,29)$. Quantification includes measurement of level of differentiation and modulation of various behavioral systems, namely: 1) autonomic or physiologic system, 2) the motor organizational system, 3) the state organizational system, 4) the attention-interaction system and 5) the selfregulation system, reflecting the infant's pattern of current behavioral organization and integration, which takes also into account 6 ) the examiner facilitation necessary to regulate the preterm infant's behavior. These scores are referred to as the "system scores" and identify the differential subsystem stability of the infant. They are considered to be the key parameters of the APIB and are the neurobehavioral measures used in this study. The examinations were performed in a quiet room, where lighting was indirect and soft. Scoring was performed according to the well-established procedure (28). All five system scores range from 1 to 9,1 reflecting best performance and 9 compromised performance with poor behavioral differentiation. Interobserver reliability in administration and scoring was achieved by an established training process.

Statistical analysis. Statistical analysis was performed using SPSS for Windows (SPSS Inc., Chicago, IL, U.S.A.). Group comparison of MRI and APIB scores in IUGR and control infants was performed by $t$ test for independent means and one-way ANOVA. For comparison of Early MRI and Term MRI in the two groups of preterm infants examined at two different time points, we used a $t$ test for paired sample. MRI measures were also subjected to a two-way ANOVA (F test), testing for group, time and group by time interaction effects. Level of statistical significance was set at $p<0.05$. Pearson's correlation was calculated between the behavior score atten- tion/interaction and CGM volume in IUGR infants and controls.

\section{RESULTS}

Early quantitative volumetric MR analysis was performed within 2 wk of birth in 14 IUGR premature infants and 14 premature control infants. A full repeat MR scan protocol and detailed neurobehavioral assessment was undertaken at term in all infants.

\section{Quantitative Structural Analysis Comparing IUGR with Control Premature Infants}

Gray matter volumes: CGM and SGM. The comparison between premature infants born with IUGR due to placental insufficiency and controls showed a marked reduction in CGM absolute volume in IUGR infants shortly after birth $(p<0.01)$, which remained significantly reduced at the second examination at term $(p<0.01)$. There was a $28 \%$ reduction of CGM volume in premature infants born with IUGR relative to volume in control gestational age matched premature infants shortly after birth and a $21 \%$ reduction at term (Table 1, Fig. 1).

Relative volume of CGM as percentage of ICV in premature infants born with IUGR was smaller but not statistically different at birth (IUGR: $30.7 \pm 6.6 \% \mathrm{ICV}$; control: $35.4 \pm$ $5.7 \% \mathrm{ICV} ; p=0.09)$, but was significantly reduced when compared with relative CGM volume in control infants at term (IUGR: $34.6 \pm 3.9 \% \mathrm{ICV}$; control: $39.6 \pm 4.5 \% \mathrm{ICV} ; p<$ $0.01)$.

SGM volume, which represents the volume of basal ganglia and thalamus together, were similar between the two groups both shortly after birth and at term (Table 1).

White matter volumes: MWM and UMWM. MWM absolute volumes in premature infants with IUGR were not statistically different from the volumes in the control infants in both early and term MRI. The volume of UMWM was very similar between the two groups (Table 1).

CSF volumes. There was no significant difference in CSF absolute volume between IUGR infants and control premature infants in early and term MRI examinations (Table 1).

ICV and total brain tissue volumes. ICV (a summation of CGM, MWM, UMWM, SGM, and both intraventricular and extracerebral CSF) was also calculated as an overall assess-

Table 1. Early MRI and term MRI: comparison of cerebral tissue volumes (as absolute volume (mL)) in premature infants born with IUGR and control premature infants

\begin{tabular}{|c|c|c|c|c|c|c|}
\hline \multirow[b]{2}{*}{ Brain region } & \multicolumn{3}{|c|}{ Early MRI } & \multicolumn{3}{|c|}{ Term MRI } \\
\hline & IUGR & Control & $p$ Value & IUGR & Control & $p$ Value \\
\hline Total intracranial volume & $253.7 \pm 29.9$ & $300.5 \pm 43.5$ & $<0.01$ & $429.3 \pm 47.9$ & $475.9 \pm 53.4$ & $<0.05$ \\
\hline Total brain tissue volume & $229.9 \pm 24.7$ & $270.6 \pm 41.6$ & $<0.05$ & $377.7 \pm 42.2$ & $419.3 \pm 40.3$ & $<0.05$ \\
\hline Cerebral cortical gray matter & $77.2 \pm 16.3$ & $106.8 \pm 24.6$ & $<0.01$ & $149.3 \pm 29.2$ & $189 \pm 34.2$ & $<0.01$ \\
\hline Basal ganglia/thalamus & $17 \pm 6.8$ & $16.8 \pm 1.8$ & 0.92 & $21.5 \pm 4.9$ & $22.1 \pm 4.4$ & 0.72 \\
\hline Unmyelinated white matter & $131 \pm 21.6$ & $141.3 \pm 27.7$ & 0.34 & $198.5 \pm 21.4$ & $198.6 \pm 26$ & 0.99 \\
\hline Myelinated white matter & $4.7 \pm 1.9$ & $5.7 \pm 1.8$ & 0.21 & $8.3 \pm 3.7$ & $9.5 \pm 3.7$ & 0.42 \\
\hline Cerebrospinal fluid & $23.7 \pm 9.9$ & $29.9 \pm 12$ & 0.19 & $51.6 \pm 15.7$ & $56.6 \pm 28.8$ & 0.57 \\
\hline
\end{tabular}

Values are mean $\pm \mathrm{SD}$. 


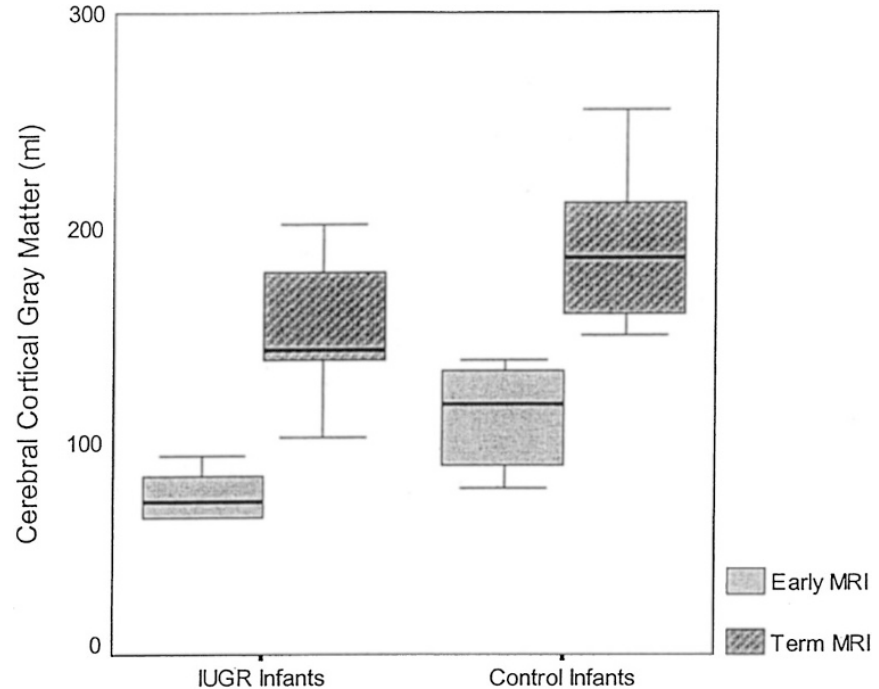

Figure 1. Cerebral cortical gray matter volumes within the first $2 \mathrm{wk}$ of life (Early MRI) and at term (Term MRI) in premature infants born with IUGR and in control premature infants (expressed as medians with $25^{\text {th }} / 75^{\text {th }}$ centile box, $10^{\text {th }} / 90^{\text {th }}$ centile error bars, and outliers).

ment of head growth. In the early MRI examination and also at term, premature infants born with IUGR had a marked reduction in ICV, compared with the volume in control infants (Early MRI: $p<0.01$; Term MRI: $p<0.05$ ) (Table 1, Fig. 2). Shortly after birth, ICV was reduced by $16 \%$ in the premature infants with IUGR relative to the control group and remained reduced by $10 \%$ at term. Total brain tissue volume (ICV excluding CSF) was also significantly reduced in premature infants born with IUGR compared with control infants in both examinations (Early MRI and Term MRI: both $p<0.05$ ) (Table 1). Total brain tissue volume reduction was similar to ICV reduction in the IUGR infants.

Analysis of covariance. The results of the repeated ANOVA of the structural brain development with MRI are as follows:

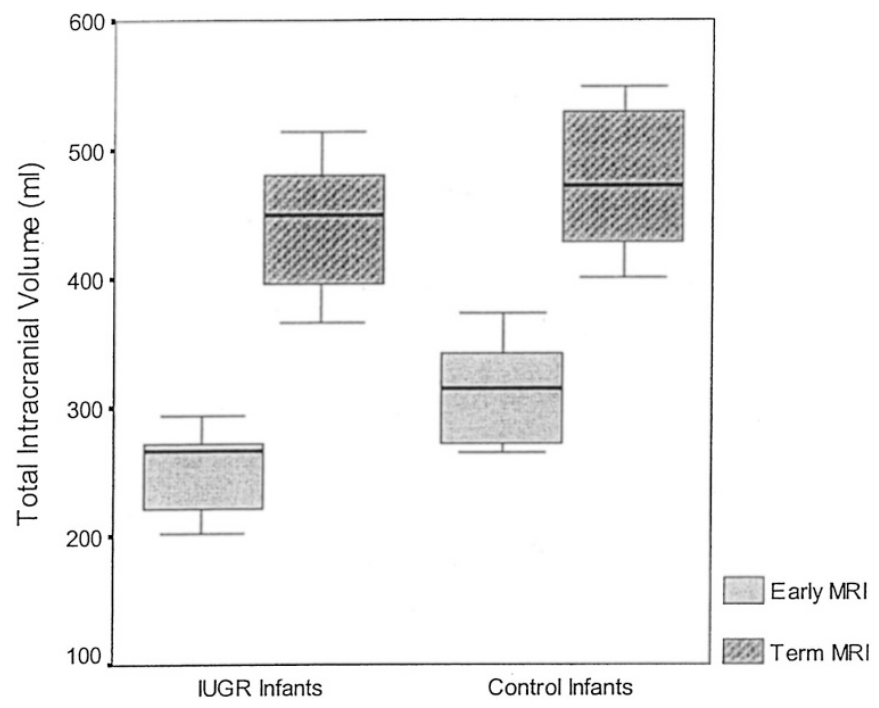

Figure 2. Total brain volumes within the first $2 \mathrm{wk}$ of life (Early MRI) and at term (Term MRI) in premature infants born with IUGR and in control premature infants (expressed as medians with $25^{\text {th }} / 75^{\text {th }}$ centile box, $10^{\text {th }} / 90^{\text {th }}$ centile error bars, and outliers). there was a significant time effect with an increase of absolute volumes of CGM $(p<0.0001), \operatorname{CSF}(p<0.0001), \operatorname{MWM}(p$ $=0.001), \operatorname{UMWM}(p<0.0001), \operatorname{SGM}(p<0.01)$, and ICV $(p$ $<0.0001$ ) from the first $2 \mathrm{wk}$ after birth to term. CGM volume and ICV showed also a significant group effect, with the IUGR infants showing a reduction of these volumes compared with control infants $(p<0.001$ and $p=0.01$, respectively $)$. There was no significant group by time interaction effect in the MRI measurements. Thus, the IUGR infants had reduced CGM volume and ICV shortly after birth and at term with no significant difference in volume increase over time (Figs. 1 and 2)

\section{Neurobehavioral Assessment}

In terms of assessment of the functional maturation, the APIB showed less mature scores in the IUGR infants compared with control infants. In particular, the attention-interaction score was significantly higher (low maturity) in IUGR patients compared with control infants because they had more difficulties in maintaining attention and responsiveness to animate and inanimate stimuli and in interacting with various social stimuli. The differences in the other neurobehavioral scores (autonomic and motor reactivity, state organization, and self-regulatory capacity) did not reach significance in the two groups (Table 2).

\section{Growth Parameters}

IUGR infants had a significantly lower body weight at term compared with body weight in control infants $(2581 \pm 351 \mathrm{~g}$, versus $3339 \pm 479 \mathrm{~g}, p<0.0001)$. Average weight gain per week from birth to $40 \mathrm{wk}$ PCA was significantly different in the two groups, with a poor weight gain in IUGR infants compared with the control group $(164 \pm 35 \mathrm{~g}$, versus $206 \pm 46 \mathrm{~g}, p=$ 0.01 ). Furthermore, there was a significant difference at term between these two groups in head growth as assessed by measurement of the occipito-frontal circumference (33.9 \pm 1.2 $\mathrm{cm}$ in IUGR infants versus $35.4 \pm 1.1 \mathrm{~cm}$ in control infants, $p$ $<0.01)$. There was no significant group by time interaction effect in body weight and head growth.

\section{Correlations between Structural and Functional Parameters}

Head circumference correlated with ICV $(r=0.86, p<$ $0.01)$ and with CGM volume $(r=0.76, p<0.01)$. CGM absolute volume at term correlated also with behavior score of attention-interaction capacity $(r=0.45, p<0.05)$ (Fig. 3).

Table 2. Behavioral assessment (APIB)

\begin{tabular}{lccc}
\hline & IUGR & Control & $p$ Value \\
\hline Autonomic & $5.2 \pm 0.8$ & $4.6 \pm 0.6$ & 0.06 \\
Motor & $5.3 \pm 1$ & $4.7 \pm 0.8$ & 0.1 \\
State organizational & $4.9 \pm 1$ & $5 \pm 0.8$ & 0.8 \\
Attention/interaction & $6 \pm 1.2$ & $4.8 \pm 0.9$ & $<0.01$ \\
Self-regulation & $5.1 \pm 0.9$ & $5 \pm 0.9$ & 0.9 \\
Examiner facilitation & $4.1 \pm 1$ & $4.3 \pm 1.5$ & 0.7
\end{tabular}

Mean and SD of the APIB subsystem scores for the IUGR and control groups derived from the behavioral examination at term. All system scores are scaled from 1 to 9 , with 1 representing well-organized performance and 9 representing poorly organized performance. 


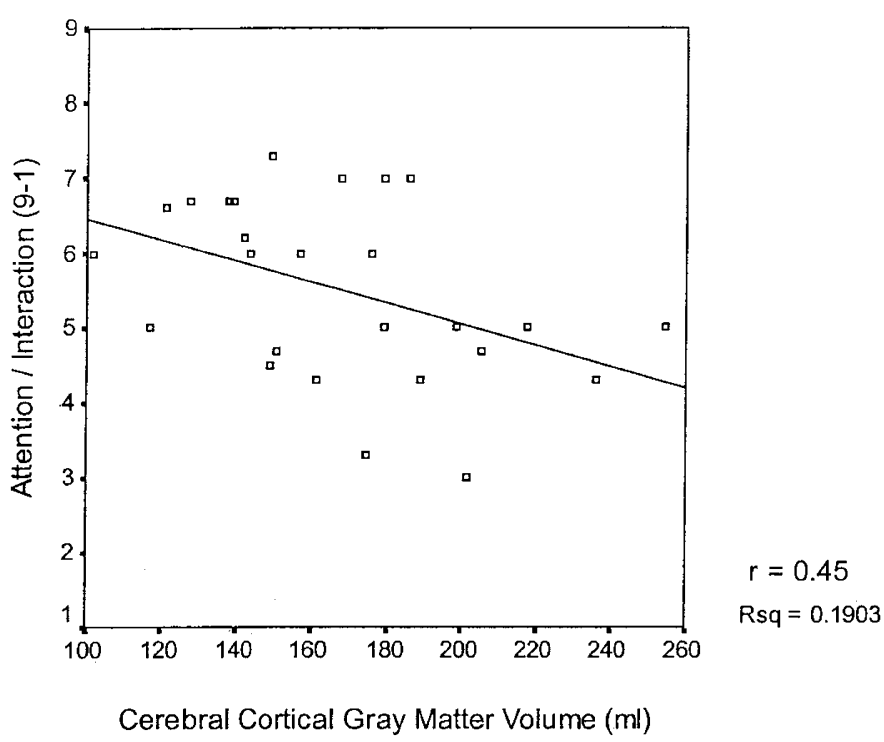

Figure 3. Pearson's correlation between the behavior score attention/ interaction and CGM volume at term in IUGR preterm infants and control preterm infants. The linear regression model fits the data with $r=0.45, p<$ 0.05 .

\section{DISCUSSION}

This study demonstrates significant alterations in brain tissue volumes in preterm infants born with IUGR using in vivo 3D quantitative volumetric MRI with tissue segmentation. These findings point to a first biologic correlate for the well-described association of IUGR with later neurodevelopmental deficit (30).

The present study also documents differences in neurobehavioral outcome at term between preterm infants born with IUGR and preterm infants without IUGR.

Effects of IUGR on brain tissue volumes. The predominant neurostructural difference observed in the IUGR infants compared with gestational age-matched control infants was found in the cortical gray matter, with a significant reduction in absolute cortical gray matter volume. Cortical gray matter volume in IUGR infants was reduced by $28 \%$ compared with control infants shortly after birth and remained reduced at term. This difference was not accompanied by any change in volume of CSF in IUGR infants compared with controls and no difference in white matter volumes both myelinated and nonmyelinated. Toft et al. (31), using semi-quantitative assessment of MRI at term, had suggested in an earlier study that effects of IUGR decreased the gray-to-white matter ratio, suggesting that fetal growth restriction reduces gray matter volume more than white matter.

As an expression of combined intrauterine and postnatal brain growth, overall brain tissue volumes were measured at term and showed a $10 \%$ reduction in IUGR infants compared with control infants, the latter showing similar total brain tissue volumes documented for preterm infants at term in our prior studies $(24,25)$

Relative cortical gray matter volume given as percentage of total intracranial volume was reduced in IUGR infants and confirmed the selective reduction of cortical gray matter vol- ume in IUGR infants compared with control infants, indicating that mechanisms involved in reduced brain growth in IUGR predominantly affected cerebral cortical development. Both total brain tissue volume and cortical gray matter volume change over time showed no catch-up growth in our IUGR group. As this was a short period of time, further follow-up of this population at 18 mo will determine whether this holds true.

Insights into the pathogenesis of the cerebral alteration associated with IUGR due to poor placental function. Several important pathophysiologic mechanisms occur during IUGR due to poor placental function. Hemodynamic changes lead to repetitive episodes of hypoxemia $(6,32)$ and placental trophoblast cell dysfunction leads to loss of nutrients and alteration of placental hormone homeostasis $(7,33)$. There is strong neuropathologic evidence for a deleterious effect of early malnutrition and IUGR on brain development, with a reduction in cell number and cell size with overall lower brain weight $(19,34$, 35). Experimental studies in different animal models of IUGR have shown neuronal degeneration in the hippocampal pyramidal neurons and loss of dendritic branches and density of granular neurons in the dentate gyrus, with an overall reduction of cellularity by $30 \%$ (36), which resulted in reduced overall hippocampal volume measured by MRI (37).

There is growing evidence that the neuroendocrine consequences of fetal malnutrition and IUGR (38) are mainly in the modification of the hypothalamo-pituitary-adrenal (HPA) axis. Umbilical cord plasma levels of corticotropin-releasing hormone have been shown to be markedly elevated in IUGR fetuses (39), and fetal cortisol levels were found to be higher in IUGR than control infants (40). Recent quantitative MRI studies evaluating the effects of repeated antenatal glucocorticoid therapy and postnatal corticosteroid therapy found significant reductions in the overall brain surface and in cortical gray matter volume to a similar degree as in our group of IUGR infants $(41,42)$. Further studies will be needed to test the hypothesis that the changes in early cortical development that are observed in IUGR might be related to the alteration of the brain by the neuroendocrine consequences of IUGR.

Consequences of hemodynamic changes occurring in placental insufficiency have been evaluated in recent animal studies showing reduction in myelin staining in the cerebral white matter $(19,43)$. As part of our study recruitment, but not part of the current analysis, we identified one infant with IUGR and white matter injury. This infant's volumetric assessment at term showed reduced total brain volume, reduced myelinated white matter, and reduced cortical gray matter volume, analogous to our earlier published series of periventricular white matter injury (25). Our population of IUGR infants showed similar volumes of myelinated white matter as their agematched control infants. In the absence of ischemic white matter injury, white matter does not seem to be affected by IUGR.

Effects of IUGR on postnatal growth at term. Total intracranial volume and brain tissue volume increased from birth to term in both the IUGR and control groups. Despite a small trend toward a decrease in differences between groups at term, intracranial volume and cortical gray matter volume in IUGR infants remained smaller at term without significant catch-up 
growth. This indicates that the cortical gray matter volume differences seen shortly after birth are not transitory, as they persist at term to a similar degree.

Although postnatal catch-up growth occurs in the majority of IUGR infants, in our study the anthropometric measurements at term demonstrated that infants born with IUGR after placental insufficiency were of significantly lower weight and had smaller head circumference than the control group, with no significant catch-up from the first $2 \mathrm{wk}$ after birth to term. Our subjects exhibited a weight increase with time, but the average weight gain per week from birth to term was significantly lower in the IUGR group. Cianfarani et al. (44) studied children who were born with IUGR and observed an inverse relationship between cortisol and birth weight as well as an inverse relationship between catch-up growth at $9 \mathrm{y}$ and plasma cortisol levels in IUGR children: the higher the cortisol concentrations, the lower the catch-up growth. In several outcome studies, absence of catch-up head growth has been strongly associated with neurodevelopmental impairment in childhood $(45,46)$. Follow-up of our study population beyond the neonatal period will determine effects of IUGR on long-term growth.

Effects of IUGR on early neurobehavioral functions. Differences in early neurobehavior between preterm infants at term and full-term infants have been reported (47-49), but there are no data related to premature infants with IUGR so far. We were able to measure neuro-functional outcome at term in all six subsystem categories measured by the APIB (28). In the premature infants born with IUGR, our MRI findings were paralleled by significantly less mature scores in the APIB, particularly in the subsystem of attention interaction capacity compared with the control group. Likewise, IUGR infants had a trend toward less motor maturity and greater disorganization in the autonomic state. The scores for state organization, self-regulatory ability, and the complementary amount of examiner facilitation needed to achieve balance did not differ between the two groups.

To assess the relationship of these neurobehavioral scores with neurostructural development, correlation analysis was performed between the MRI parameters and the neurobehavioral scores. A significant correlation between cerebral cortical gray matter volume and the attention interaction capacity measured at term was detected. This is, to our knowledge, the first prospective study to demonstrate that quantitative structural MRI findings correlate with measures of neurobehavioral maturation.

Clinical implications. Several studies of infants born prematurely evaluated by quantitative volumetric MRI in late childhood have shown reductions in brain volumes and also correlations of these reductions with impaired neurodevelopmental outcome $(50,51)$ and deficits in everyday memory $(52)$ and global cognitive functioning. In outcome studies of IUGR infants with documented signs of placental insufficiency, neurodevelopmental outcome has been characterized predominantly by cognitive impairment at 5,7 , and 9 y of age (2, 53-55). Hence, our data support the hypothesis that the principal alterations in brain development in IUGR preterm infants occur in cerebral cortex, persist to term age, and disrupt behavioral function at term. Further follow-up of our population will determine the value of quantitative structural MRI and functional performances measured by term neurobehavioral assessment as predictive markers for long-term neurodevelopmental outcome in this high-risk population.

Acknowledgments. The authors thank F. Henri for the technical assistance, Dr. Joseph Volpe for his scientific advice and support, and, finally, the families and infants of the cohort.

\section{REFERENCES}

1. Toft PB 1999 Prenatal and perinatal striatal injury: a hypothetical cause of attentiondeficit-hyperactivity disorder? Pediatr Neurol 21:602-610

2. Kok JH, den Ouden AL Verloove-Vanhorick SP, Brand R 1998 Outcome of very preterm small for gestational age infants: the first nine years of life. Br J Obstet Gynaecol 105:162-168

3. Barker DJ 1995 Fetal origins of coronary heart disease. BMJ 311:171-174

4. Seck1 JR, Cleasby M, Nyirenda MJ 2000 Glucocorticoids, 11beta-hydroxysteroid dehydrogenase, and fetal programming. Kidney Int 57:1412-1417

5. Newnham J 1998 Consequences of fetal growth restriction. Curr Opin Obstet Gynecol 10:145-149

6. McMillen IC, Adams MB, Ross JT, Coulter CL, Simonetta G, Owens JA, Robinson JS, Edwards LJ 2001 Fetal growth restriction: adaptations and consequences. Reproduction 122:195-204

7. Gluckmann PD, Harding JE 1997 Fetal growth retardation: underlying endocrine mechanisms and postnatal consequences. Acta Paediatr Suppl 422:69-72

8. Seckl JR 1997 Glucocorticoids, feto-placental 11 beta-hydroxysteroid dehydrogenase type 2, and the early life origins of adult disease. Steroids 62:89-94

9. Low JA, Galbraith RS, Muir D, Killen H, Pater B, Karchmar J 1982 Intrauterine growth retardation: a study of long-term morbidity. Am J Obstet Gynecol 142:670677

10. Regev RH, Lusky A, Dolfin T, Litmanovitz I, Arnon S, Reichman B, Israel Neonatal Network 2003 Excess mortality and morbidity among small-for-gestational-age premature infants: a population-based study. J Pediatr 143:186-191

11. Alkalay AL, Graham Jr JM, Pomerance JJ 1998 Evaluation of neonates born with intrauterine growth retardation: review and practice guidelines. J Perinatol 18:142151

12. Strauss RS, Dietz WH 1998 Growth and development of term children born with low birth weight: effects of genetic and environmental factors. J Pediatr 133:67-72

13. Low JA, Handley-Derry MH, Burke SO, Peters RD, Pater EA, Killen HL, Derrick EJ 1992 Association of intrauterine fetal growth retardation and learning deficits at age 9 to 11 years. Am J Obstet Gynecol 167:1499-1505

14. Sung IK, Vohr B, Oh W 1993 Growth and neurodevelopmental outcome of very low birth weight infants with intrauterine growth retardation: comparison with control subjects matched by birth weight and gestational age. J Pediatr 123:618-624

15. Nelson KG, Goldenberg RL, Hoffman HJ, Clive SP. 1997 Growth and developmen during the first year in a cohort of low income term-born American children. Acta Obstet Gynecol Scand Suppl 165:87-92

16. Gottleib S, Biasini F, Bray N 1988 Visual recognition memory in IUGR and normal birthweight infants. Infant Behav Devel 11:223-228

17. Dietrich RB, Bradley WG, Zaragoza IV EJ, Otto RJ, Taira RK, Wilson GH, Kangarloo H 1988 MR evaluation of early myelination patterns in normal and developmentally delayed infants. Am J Roentgenol 150:889-896

18. Mallard C, Loeliger M, Copolov D, Rees S 2000 Reduced number of neurons in the hippocampus and the cerebellum in the postnatal guinea-pig following intrauterine growth-restriction. Neuroscience 100:327-333

19. Mallard E, Rees S, Stringer M, Cook ML, Harding R 1998 Effects of chronic placental insufficiency on brain development in fetal sheep. Pediatr Res 43:262-270

20. Cragg B 1972 The development of cortical synapses during starvation in the rat. Brain 95:143-150

21. Winick M, Rosso P 1969 The effect of severe early malnutrition on cellular growth of the human brain. Pediatr Res 3:181-184

22. Arbuckle TE, Wilkins R, Sherman GJ 1993 Birth weight percentiles by gestational age in Canada. Obstet Gynecol 81:39-48

23. Sonesson SE, Fouron JC, Drblik SP, Tawile C, Lessard M, Skoll A, Guertin MC Ducharme GR 1993 Reference values for Doppler velocimetric indices from the fetal and placental ends of the umbilical artery during normal pregnancy. J Clin Ultrasound 21:317-324

24. Hüppi PS, Warfield S, Kikinis R, Barnes PD, Zientara GP, Jolesz FA, Tsuji MK, Volpe JJ 1998 Quantitative magnetic resonance imaging of brain development in premature and mature newborns. Ann Neurol 43:224-235

25. Inder TE, Hüppi PS, Warfield S, Kikinis R, Zientara G, Barnes PD, Jolesz F, Volpe JJ 1999 Periventricular white matter injury in the premature infant is followed by reduced cerebral cortical gray matter volume at term. Ann Neurol 46:755-760

26. Warfield SK, Kaus M, Jolesz FA, Kikinis R 2000 Adaptive, template moderated, spatially varying statistical classification. Med Image Anal 4:43-55

27. Brazelton T 1973 Neonatal Behavioral Assessment Scale. Clinic in Developmental Medicine 50. JB Lippincott, Philadelphia, pp 1-66

28. Als H, Lester B, Tronick E, Brazelton T 1982 Towards a research instrument for the assessment of preterm infant's behavior (APIB) and manual for the assessment of 
preterm infant's behavior (APIB). In: Fitzgerald HE, Lester BM, Yogman MW (eds) Theory and Research in Behavioral Pediatrics. Plenum Publishing, New York, pp $35-63$

29. Buehler DM, Als H, Duffy FH, McAnulty GB, Liederman J 1995 Effectiveness of individualized developmental care for low-risk preterm infants: behavioral and electrophysiologic evidence. Pediatrics 96:923-932

30. O'Keeffe MJ, O'Callaghan M, Williams GM, Najman JM, Bor W 2003 Learning, cognitive, and attentional problems in adolescents born small for gestational age. Pediatrics 112:301-307

31. Toft PB, Leth H, Ring PB, Peitersen B, Lou HC, Henriksen O 1995 Volumetric analysis of the normal infant brain and in intrauterine growth retardation. Early Hum Dev 43:15-29

32. Owens JA, Falconer J, Robinson JS 1987 Effect of restriction of placental growth on oxygen delivery to and consumption by the pregnant uterus and fetus. J Dev Physiol 9:137-150

33. Regnault TR, Orbus RJ, Battaglia FC, Wilkening RB, Anthony RV 1999 Altered arterial concentrations of placental hormones during maximal placental growth in a model of placental insufficiency. J Endocrinol 162:433-442

34. Rees S, Breen S, Loeliger M, McCrabb G, Harding R 1999 Hypoxemia near mid-gestation has long-term effects on fetal brain development. J Neuropathol Exp Neurol 58:932-945

35. Rees S, Harding R 1988 The effects of intrauterine growth retardation on the development of the Purkinje cell dendritic tree in the cerebellar cortex of fetal sheep: a note on the ontogeny of the Purkinje cell. Int J Dev Neurosci 6:461-469

36. Uno H, Lohmiller L, Thieme C, Kemnitz JW, Engle MJ, Roecker EB, Farrell PM 1990 Brain damage induced by prenatal exposure to dexamethasone in fetal rhesus macaques. I. Hippocampus. Brain Res Dev Brain Res 53:157-167

37. Uno H, Eisele S, Sakai A, Shelton S, Baker E, DeJesus O, Holden J 1994 Neurotoxicity of glucocorticoids in the primate brain. Horm Behav 28:336-348

38. Barker DJ, Gluckman PD, Godfrey KM, Harding JE, Owens JA, Robinson JS 1993 Fetal nutrition and cardiovascular disease in adult life. Lancet 341:938-941

39. Goland RS, Jozak S, Warren WB, Conwell IM, Stark RI, Tropper PJ 1993 Elevated levels of umbilical cord plasma corticotropin-releasing hormone in growth-retarded fetuses. J Clin Endocrinol Metab 77:1174-1179

40. Economides DL, Nicolaides KH, Campbell S 1991 Metabolic and endocrine findings in appropriate and small for gestational age fetuses. J Perinat Med 19:97-105

41. Modi N, Lewis H, Al Naqeeb N, Ajayi-Obe M, Dore CJ, Rutherford M 2001 The effects of repeated antenatal glucocorticoid therapy on the developing brain. Pediatr Res 50:581-585

42. Murphy BP, Inder TE, Hüppi PS, Zientara GP, Warfield S, Zientara GP, Kikinis R, Jolesz FA, Volpe JJ 2001 Impaired cerebral cortical gray matter growth following treatment with dexamethasone for neonatal chronic lung disease. Pediatrics 107:217221

43. Duncan JR, Cock ML, Harding R, Rees SM 2000 Relation between damage to the placenta and the fetal brain after late-gestation placental embolization and fetal growth restriction in sheep. Am J Obstet Gynecol 183:1013-1022

44. Cianfarani S, Geremia C, Scott CD, Germani D 2002 Growth, IGF system, and cortisol in children with intrauterine growth retardation: is catch-up growth affected by reprogramming of the hypothalamic-pituitary-adrenal axis? Pediatr Res 51:94-99

45. Frisk V, Amsel R, Whyte HE 2002 The importance of head growth patterns in predicting the cognitive abilities and literacy skills of small-for-gestational-age children. Dev Neuropsychol 22:565-593

46. Hack M, Breslau N, Weissman B, Aram D, Klein N, Borawski E 1991 Effect of very low birth weight and subnormal head size on cognitive abilities at school age. N Engl J Med 325:231-237

47. Als H, Duffy F, McAnulty G 1988 Behavioral differences between preterm and fullterm newborns as measured with the APIB system scores. Infant Behav Dev 11:305-318

48. Als H, Lawhon G, Duffy FH, McAnulty GB, Gibes-Grossman R, Blickman JG 1994 Individualized developmental care for the very low-birth-weight preterm infant. Medical and neurofunctional effects. JAMA 272:853-858

49. Hüppi P, Schuknecht B, Boesch C, Bossi E, Felblinger J, Fusch C, Herschkowitz N 1996 Structural and neurobehavioral delay in postnatal brain development in preterm infants. Pediatr Res 39:895-901

50. Peterson BS, Vohr B, Staib LH, Cannistraci CJ, Dolberg A, Schneider KC, Katz KH, Westerveld M, Sparrow S, Anderson AW, Duncan CC, Makuch RW, Gore JC, Ment LR 2000 Regional brain volume abnormalities and long-term cognitive outcome in preterm infants. JAMA 284:1939-1947

51. Peterson BS, Anderson AW, Ehrenkranz R, Staib LH, Tageldin M, Colson E, Gore JC, Duncan CC, Makuch R, Ment LR 2003 Regional brain volumes and their late neurodevelopmental correlates in term and preterm infants. Pediatrics 111:939-948

52. Isaacs EB, Lucas A, Chong WK, Wood SJ, Johnson CL, Marshall C, Vargha-Khadem F, Gadian DG 2000 Hippocampal volume and everyday memory in children of very low birth weight. Pediatr Res 47:713-720

53. Scherjon S, Briet J, Oosting H, Kok J 2000 The discrepancy between maturation of visual-evoked potentials and cognitive outcome at five years in very preterm infants with and without hemodynamic signs of fetal brain-sparing. Pediatrics 105:385-391

54. Ley D, Laurin J, Bjerre I, Marsal K 1996 Abnormal fetal aortic velocity waveform and minor neurological dysfunction at 7 years of age. Ultrasound Obstet Gynecol $8: 152-159$

55. Schreuder AM, McDonnell M, Gaffney G, Johnson A, Hope PL 2002 Outcome at school age following antenatal detection of absent or reversed end diastolic flow velocity in the umbilical artery. Arch Dis Child Fetal Neonatal Ed 86:F108-F114 